\title{
Principal Component Analysis of Industrial Sector Electricity Consumption Drivers in Nigeria
}

\author{
O Y Usman ${ }^{1 *}$ K Abdullah $^{2}$, A N Mohammed ${ }^{3}$ \\ ${ }^{1}$ Faculty of Mechanical and Manufacturing Engineering, Universiti Tun Hussein Onn, Malaysia, Parit Raja, \\ 86400, Malaysia., Malaysia, 2011.itosman@gmail.com \\ ${ }^{2}$ Faculty of Mechanical and Manufacturing Engineering, Universiti Tun Hussein Onn, Malaysia, Parit Raja, \\ 86400, Malaysia, Malaysia, mkamil@uthm.edu.my \\ ${ }^{3}$ Faculty of Mechanical and Manufacturing Engineering, Universiti Tun Hussein Onn, Malaysia, Parit Raja, \\ 86400, Malaysia, Malaysia, akmaln@uthm.edu.my
}

\begin{abstract}
The paper aims to determine and evaluate the principal components responsible for driving industrial sector's electricity consumption in Nigeria. Six industrial electricity consumption variables were initially chosen which on examining their properties indicated severe multi-collinearity. That means the analysis would yield unreliable estimates if linear regression approach was used. The principal component analysis was carried out using $\mathrm{R}$ statistical software. The result of analysis of these variables produced two outstanding principal components having maximum Eigen-values of 2.365 and 0.444 , correspondingly, as well as cumulative variance of 0.932 and 0.965 , respectively. Industrial electricity consumption was regressed on these two components and the results revealed that the two components affected electricity consumption in varying numerical strengths. The implication of this result is the urgent need to put in place appropriate institutional and policy measures to shore up the supply of reliable and adequate amount of electricity to the industrial sector in the face of growing industrial electricity consumption profile. That will pave way for rapid and sustainable socio-economic growth of the nation.
\end{abstract}

Key words: components; electricity consumption; industrial; regression; variables.

\section{INTRODUCTION}

Electricity is an indispensable and critical input for socio-economic transformation of any nation. In the industrial sector, electricity is viewed as a critical factor of production and as such it is linked to technology advancement, industrialization as well as the need to meet the basic human needs of modern comfort such as warmth, lighting, cooling, nutrition and public health [1]. However, ensuring ample and sustained supply of electricity in addition to the environmental consequences of consuming, particularly, fossil fuel-based energy resources has aroused global concern in recent decades.
Adequate and reliable supply of electricity enhances better living standards and generous wealth creation in all countries of the world. Besides, electricity production and consumption level serves as a benchmark for determining respective nation's level of socio-economic status [2]. This criterion particularly shows disparity in income levels as well as electricity content of economic growth of different economies. In addition, a sustainable, safe and efficient electricity supply and utilization curtails rural-urban migration with its attendant socio-economic challenges by up-scaling the development of rural economy. Furthermore, the capacity to preserve and transform local resources into products for local and international markets is enhanced by sustained adequate supply of electricity.

With the advent of electric cars and trains, mobility of goods, labour and services has witnessed a boost. Adequate supply of electricity attracts foreign investors which promotes transfer of technology, boosts employment, discourages capital flight from a country and engenders impressive gross domestic product performance. It leverages on poverty reduction, catalyzes industrial growth and boosts the share of the industrial sector in a country's gross domestic product. This will go a long way to transform the export structure of a country in the attempt to achieve industrialization by facilitating the dominance of the industrial sector over the primary sector.

The level of industrialization of any nation is largely dependent on sufficient availability of energy in the right form and quantity, at affordable cost and such that its consumption is sustainable and does not unduly impact negatively on the environment. So, naturally, an increase in industrial activities, demands a commensurate energy supply as energy is required for both the production and consumption of goods and services in any economy [3]. For that reason, a working knowledge of the parameters that modifies the boundary conditions of the present and future energy demand is a critical component of every nation's efforts to stimulate and sustain increased economic transformation and global relevance. 
At present, the Nigerian government has a policy objective of achieving a sustained annual economic growth rate of $7 \%$ by 2020 as enshrined in an ambitious programme tagged "Economic Recovery and Growth Plan (ERGP)", [4]. This is aimed at rapidly expanding total production and fast-tracking overall economic development.

Industrial electricity supply in Nigeria has not been experiencing considerable growth for decades and is not healthy for the overall socio-economic wellbeing of the country, given her widely advertised zest for sustainable growth and development. Fig. 1 below shows the grossly low supply of electricity to the industrial sector in Nigeria compared to the other sectors. The figure indicates that among the three main sectors of the nation's economy namely the residential, industrial and the commercial sectors respectively, the industrial sector accesses the lowest amount of electricity supply from the national grid.

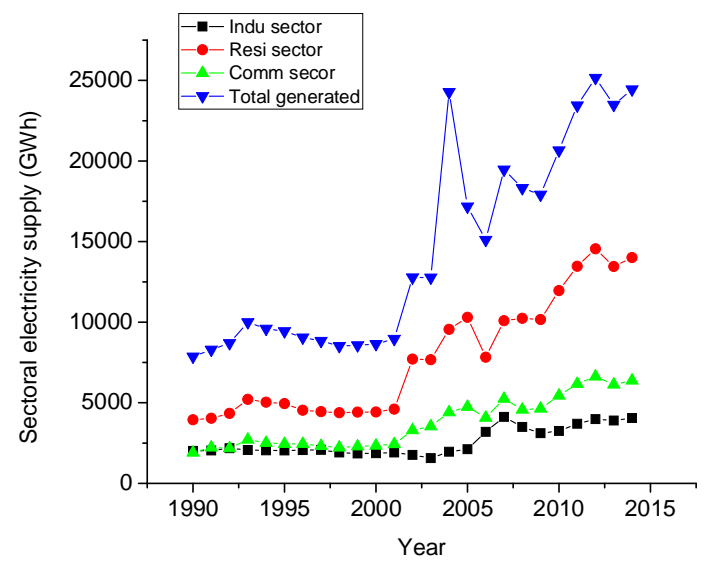

Figure 1: Electricity consumption in the various sectors Source: Data was compiled from IEA database by the researchers.

[5] listed the basic five main ways by which industries may approach inadequate and unreliable electricity supply as choice of location, factor substitution, private provision, choice of business and output reduction. [5] further submitted that all these elements are being currently witnessed among Nigerian firms, and that the most common approach has been through private provision. The position was corroborated by Oyedepo [6] who submitted that industries/companies acquire petrol or diesel generating plants of different capacities to generate their own alternative electricity 24 $\mathrm{h} /$ day for the 365 days a year In addition, the World Bank reported that $97 \%$ of industries in Nigeria operates on private electricity generating plants [7]. And that leads to reduction in industrial output and increase in the import content of the nation's industrial energy use.

This widespread reliance on electricity supply from other sources than the grid electricity by the industrial sectors tends to afflict the country's economic growth leading to a continuous reduction in the contribution of the industrial sector to the nation's gross domestic product. Another effect of this paltry and unreliable electricity supply is the increased cost of doing business in the country which culminates in high transfer cost on goods and services borne by the citizens. Besides, some industries which could not operate profitably under such power supply situation had relocated to other neighbouring countries where power supply is more adequate and reliable [8]. That meant loss of revenue to the government, a reduction in the contribution of the industrial sector to the country's economy as well as a decline in economic indicators such as employment generation opportunities and low industrial capacity utilization.

The palpable effect of gross power supply resulting in the low quantum of electricity available for consumption on the citizens is the perennial low electricity consumption per capita with which Nigeria has been known [6] In the industrial sector, an outstanding evidence of low electricity consumption by the sector is seen in the fact that in 2005 , while the residential sector accounted for $63 \%$ of the total electricity consumption, followed by the commercial sector (27\%), the industrial sector trailed with $(10 \%)$ of the total electricity consumption in the country [9]. This has debilitating impact on the industrial growth potentials of the Nigerian economy [10] since most industrial machines and processes are automated and are powered by electricity.

A comprehensive effort to fast pace energy development to counter this gross underutilization of electricity in the country's industrial sector includes full understanding of the nature of the parameters that dominantly influences electricity consumption in the sector. Such factors deserve due considerations in the formulation and implementation of appropriate energy policies aimed at boosting industrial productivity. They are, also, key inputs in the design of power infrastructure and energy market operations geared towards expeditious social and economic development of the nation. This is in line with the country's yearning to become one of the twentieth industrialized nations by the year 2020 christened as vision 20:2020 [11]. The vision is an initiative intended to arouse increased domestic and foreign trade in value added goods and services.

Against this background, the efforts detailed in this paper investigates the use of principal components analysis to characterize the key variables dictating electricity consumption in the industrial sector of Nigeria's economy. The technique is preferred because of its capacity to adequately handle electricity consumption data known to be vulnerable to severe multicollinearity, which when used in regression models impairs the quality and stability of such models [12]. This study contributes to literature in two ways. Firstly, to the best of the authors' knowledge this will be the first study analyzing Nigeria's industrial electricity consumption using principal component analysis technique. Secondly, while most of the studies found in literature investigated electricity consumption in Nigeria at aggregate level, not much study is seen to have examined electricity consumption at sectoral level with particular reference to industrial electricity consumption. The rest of the paper is organized as follows: Section 2 describes the data and methodology employed in the analysis; Section 3 details the 
O Y Usman et al., International Journal of Advanced Trends in Computer Science and Engineering, 8(1.3), 2019, $270-275$

results and discusses the implications of the results; Section 4 concludes the paper.

\section{DATA AND METHODOLOGY}

\subsection{Data Collection}

These variables used in the study were chosen from literature which reported similar studies in other climes. All the data used in the study are secondary data, obtained from the website of the International Energy Agency (IEA). They are measured annual data frame covering a period of 1990 to 2015. Initially, six independent variables were considered, namely gross domestic product (USD billions), consumer price index (\%), population (millions), total electricity generated $(\mathrm{GW})$, total primary energy produced (toe) and carbon dioxide emission $\left(\mathrm{CO}_{2}\right)$. The afore mentioned variables will be represented in this paper as $\mathrm{x} 1, \mathrm{x} 2, \mathrm{x} 3, \mathrm{x} 4, \mathrm{x} 5$ and $\mathrm{x} 6$ respectively

\subsection{Data Examination}

The table of all the variables obtained was first prepared and inspected in order to ensure that all the values were properly represented and that cases of missing values or outliers were identified and treated accordingly before the data is deployed for further analysis. That was done to ensure that all the collected data were in such form that they will not generate misleading results in the course of the regression analysis or undermine the model's accuracy [13]. The variables' table shows the six variables had no missing values and there was no case of outlier. Table 1 shows the Pearson's correlation coefficients, which indicates the degree and strength of linear associations between all the variables selected for this study. Each correlation coefficient in the correlation matrix, usually, has a value ranging from -1 to +1 where -1 indicates negative correlation, 0 represents no correlation and +1 is positive correlation accuracy [13], [14].Majority of the correlation coefficients in Table 1 shows strong positive correlation between the variables.

Table 1: Correlation coefficients of predictor variables

\begin{tabular}{ccccccc}
\hline & $\mathbf{x 1}$ & $\mathbf{x 2}$ & $\mathbf{x 3}$ & $\mathbf{x 4}$ & $\mathbf{x 5}$ & $\mathbf{x 6}$ \\
\hline x1 & 1.000 & 0.918 & 0.972 & 0.956 & 0.978 & 0.853 \\
x2 & 0.918 & 1.000 & 0.903 & 0.900 & 0.917 & 0.834 \\
x3 & 0.972 & 0.903 & 1.000 & 0.921 & 0.995 & 0.909 \\
x4 & 0.956 & 0.900 & 0.921 & 1.000 & 0.938 & 0.849 \\
x5 & 0.978 & 0.917 & 0.995 & 0.938 & 1.000 & 0.930 \\
x6 & 0.853 & 0.834 & 0.909 & 0.849 & 0.930 & 1.000 \\
\hline
\end{tabular}

Figure 2 below shows is a scatterplot of selected predictor variables, graphically indicates the kind of association between the variables. The figure clearly shows the prevalence of strong linear relationship between various pairs of the variables. Such strong linear dependence confirms the presence of strong multicollinearity between the variables. Furthermore, the correlation coefficients shown in Table 1 are all above the threshold of 0.8 , which also implies the existence of severe multicollinearity as was reported by [15]. The consequence of the explanatory variables being this highly dependent is that the ordinary least square estimates will hardly produce significant regression coefficients [16] . As such principal component regression analysis technique would be used for further analysis.

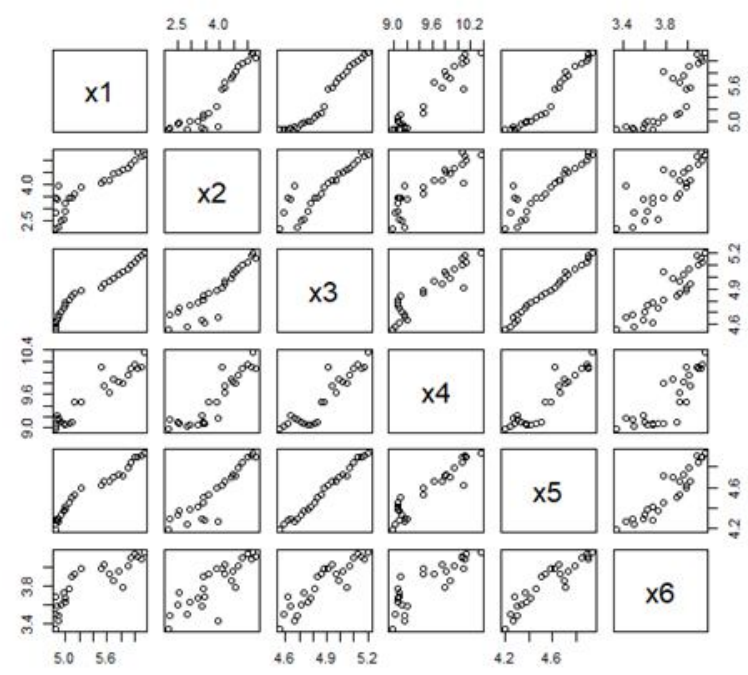

Figure 2: Scatterplot of all the predictor variables

\subsection{Principal Component Analysis (PCA)}

PCA is a statistical technique employed for the reduction of the dimensions of a complex and highly correlated data set to a smaller data set. The new smaller sets of variables formed are uncorrelated and conveys reasonably significant representation of the information contained in the original dataset [14], [17]. The main components obtained from the principal component analysis known as the principal components are linear combinations of the original variables accounting for the common and unique variability explained by them.

Given an entire table to be analyzed be represented by a matrix $\mathrm{X}$ and

$$
\mathrm{X}=I \times \mathrm{X} J
$$

where $I$ refer to observations and $J$ refers to variables.

The essence of preprocessing the linearly correlated variables before the analysis is to center the columns of $\mathrm{X}$ so that the main of each column is equal to 0 . That means

$$
\mathrm{X}^{\mathrm{T}} \mathrm{I}=0
$$

where 0 is a $J$ by 1 vector of zeros and 1 is an $I$ x 1 vector of ones.

Beside centering the columns, when the variables are measured with different units, each variable would need to be standardized to a unit norm. This is achieved by dividing each variable by its norm, which is the square root of the sum of all the squared elements of the variables. In that case, the analysis is referred to a correlation PCA, since the generated matrix is a correlation matrix [18].

PCA undergoes the following steps in transforming linearly correlated variables to uncorrelated variables: (i) extraction 
of initial components, (ii) determination of significant components, retained in a model, (iii) rotation of the matrix based on factor loadings to obtain a solution, (iv) interpretation of the solution, (v) computation of scores for each factor and of general scores, (vi) presentation of the output in a table for interpretation [19]

\subsection{Principal Component Regression (PCR)}

Having selected the principal components based on their Eigen values and the variability in the dependent variable that the principal components can explain, we used them in principal component regression analysis. The industrial sector electricity consumption was regressed on the selected two principal components in order to assess the statistical significance of the individual principal components selected as well as the overall model developed [20]. Based on the nature of the output of the principal component regression, we made appropriate recommendations with respect to energy policy, electricity generation and energy market operations.

\section{RESULTS AND DISCUSSIONS}

The result of the principal component analysis indicating the loadings generated by the analysis is shown in Table 2 .

Table 2: Loadings of the principal components

\begin{tabular}{lcccccc}
\hline \multicolumn{1}{c}{ Comp.1 } & \multicolumn{1}{c}{ Comp.2 } & Comp.3 Comp.4 Comp.5 Comp.6 \\
\hline X1 & -0.415 & -0.289 & 0.323 & -0.198 & 0.731 & 0.257 \\
X2 & -0.399 & -0.374 & -0.832 & 0.000 & 0.000 & 0.000 \\
X3 & -0.416 & 0.000 & 0.244 & -0.478 & -0.589 & 0.430 \\
X4 & -0.406 & -0.323 & 0.276 & 0.762 & -0.271 & 0.000 \\
X5 & -0.420 & 0.114 & 0.159 & -0.253 & 0.000 & -0.849 \\
X6 & -0.392 & 0.807 & -0.209 & 0.283 & 0.206 & 0.170 \\
\hline
\end{tabular}

The components' loadings show that, compared with the correlation coefficients indicated in Table 1, the instances of severe multicollinearity observed have been substantially addressed, thus certifying that these principal components are no longer linearly associated.

The importance of the respective principal components generated is reflected in Table 3. Those first two pair of components that explained above $80 \%$ of the cumulative variance were chosen for further analysis [21].

Table 3: Importance of components

\begin{tabular}{lcccc}
\hline Compo. & Coef. & \multicolumn{3}{l}{ Eigen-values } \\
\cline { 3 - 5 } & & Total & $\%$ variance & Cum. Var. \% \\
& & 0.9323 & 93.23 & 93.23 \\
2 & 0.365 & 0.0328 & 3.28 & 96.52 \\
3 & 0.339 & 0.0191 & 1.91 & 98.44 \\
4 & 0.283 & 0.0133 & 1.33 & 99.77 \\
5 & 0.112 & 0.0021 & 0.21 & 99.98 \\
6 & 0.035 & 0.0002 & 0.02 & 100.00 \\
\hline
\end{tabular}

Actually, the first two principal components in Table 3, contributed $96.52 \%$ of the cumulative variance while the remaining four components explains about $3.48 \%$ of the variance. And that means that these two principal components have effectively represented a high proportion of the cumulative variance of the original variables and should be regarded as the best subset of principal components to be used for the principal component regression analysis. This goes to show that despite the reduction in the number of variables that were chosen to be used for the study, the explanatory powers of the selected principal components are substantially high. Consequently, the first two components that contributes about $96.52 \%$ of the cumulative variance were chosen for further analysis. The scores of the two most important components as obtained from the principal component analysis in addition to the scores of the response variable are shown in Table 4.

Table 4: The dependent variable and the scores of the two principal components

\begin{tabular}{ccccccccc}
\hline Year & IEC & \multicolumn{1}{c}{ Comp.1 Comp.2 } & Year IEC & \multicolumn{2}{c}{ Comp.1 Comp.2 } \\
\hline 1990 & 7.609 & 3.837 & -0.579 & 2003 & 7.356 & -0.169 & 0.696 \\
1991 & 7.622 & 3.094 & -0.327 & 2004 & 7.580 & -1.219 & 0.015 \\
1992 & 7.686 & 2.361 & 0.058 & 2005 & 7.659 & -1.170 & 0.355 \\
1993 & 7.634 & 2.313 & -0.316 & 2006 & 8.070 & -1.023 & 0.064 \\
1994 & 7.623 & 2.355 & -1.110 & 2007 & 8.326 & -1.438 & -0.459 \\
1995 & 7.619 & 2.901 & -0.125 & 2008 & 8.161 & -1.738 & -0.098 \\
1996 & 7.631 & 2.479 & 0.155 & 2009 & 8.042 & -1.543 & -0.779 \\
1997 & 7.637 & 2.127 & 0.590 & 2010 & 8.086 & -2.369 & -0.110 \\
1998 & 7.559 & 2.065 & 0.152 & 2011 & 8.216 & -2.891 & 0.037 \\
1999 & 7.526 & 1.730 & 0.201 & 2012 & 8.290 & -3.282 & 0.069 \\
2000 & 7.532 & 1.292 & 0.460 & 2013 & 8.268 & -3.430 & -0.110 \\
2001 & 7.557 & 0.881 & 0.855 & 2014 & 8.308 & -3.467 & -0.189 \\
2002 & 7.475 & 0.290 & 0.648 & 2015 & 8.334 & -3.985 & -0.150
\end{tabular}

The result of the principal component regression analysis is shown below (Table 5). The principal component regression analysis shows that the two components on which the industrial sector electricity consumption was regressed were statistically significant with each having a probability value far less than $5 \%$, that is, $2.6 \times 10^{-08}$ and 0.0011 respectively. The model itself has a probability value of $2.701 \times 10^{-08}$ and that shows it is substantially statistically significant. The intercept as well as is also shown to be statistically significant at $95 \%$ confidence level. The regression model's coefficient of determination, $\mathrm{R}^{2}$, is 0.7803 and the model's F-statistic is 40.48 which provides sufficient evidence to show that the principal component regression model produces a good fit to the data. In addition, it provides satisfactory proof to confirm that the independent variables are statistically significant.

Table 5: Result of regression analysis

\begin{tabular}{llll}
\hline Parameter & Coefficient & P-Value & t-stat \\
\hline Intercept & 7.82327 & 2e-16 & 250.904 \\
Compo.1 & -0.11068 & $2.61 \mathrm{e}-08$ & -8.233 \\
Compo.2 & -0.26710 & 0.0011 & -3.729 \\
$\mathrm{R}^{2}=0.7803 ;$ & F-stat: $40.48:$ & P-value $=2.701 \mathrm{e}-{ }^{08}$
\end{tabular}

The result further shows that the gross domestic product (GDP), (transformed by the principal analysis technique and renamed as comp.1), contrary to expectation, has negative 
effect on electricity consumption. That is contrary to the economic theory which postulates that a boost in economic activity, represented by the values of the GDP should naturally result in an increase in electricity demand [22], [23]; [2]. Since that is the reason why electricity consumption content is globally used as a measure of industrialization, it goes to show that the rate of industrialization in the country is sluggish. This calls for responsive action by government to stimulate economic activity by boosting electricity supply and consumption in the sector. On the other hand, and as expected, the coefficient of the proxy for electricity price, consumer price index, has the expected negative sign. The sign of the variable means that a $\$ 100.00$ (the local currency) increase in the electricity price from the present tariff would lead to a decrease in electricity demand by about $26.7 \mathrm{GWh}$ annually in the sector. This finding is critical to day-to-day profitable operations of the energy market, investment decisions and the formulation of electricity pricing policy.

\section{CONCLUSION}

In this paper, principal component analysis was employed to generate the dominant variables motivating the amount and frequency of electricity consumption in the industrial sector of Nigeria's economy. Thereafter, a principal component regression model was produced for the purpose of analyzing electricity consumption in the sector. The findings of this study suggest the following conclusions:

- That principal component analysis accords a simple and credible means of gaining an improved knowledge of key variables dictating the level of electricity in the industrial sector using time series data.

- That principal component analysis is an effective analytical tool for handling data series deplored by multicollinearity.

- That the two parameters identified to be outstanding in instigating electricity consumption in the sector should form the core of factors that should be considered with regards to energy policy, plant design and issues surrounding energy market operations geared toward efforts to ward off energy supply crisis.

- That government should facilitate steady increase in the supply of electricity to the industrial sector so as to enhance growth in industrial productivity since the operations of the other sectors largely depends on the industrial sector. That will result in accelerated socio-economic development.

- That though larger number of variables could be used in further tests on the electricity consumption in the sector, this present study is successful as it was able to identify variables that are mostly influencing electricity consumption in the sector.

\section{ACKNOWLEDGEMENT}

This research was conducted under the auspices of the Center for Energy and Industrial Environment Studies, FKMP and
UTHM IGSP Research Grant Vot. U413 under Research Management Center (RMC) Universiti Tun Hussein Onn Malaysia.

\section{REFERENCES}

[1] S. O. Oshota, "Electricity consumption and economic growth in Nigeria: Evidence from Bounds test," The empirical econometrics and quantitative economics letters, vol. 3, pp. 66-77, 2014.

[2] S. A. Yusuf, "Energy Sector is critical to Nigeria Growth and Development: Perspective to Electricity Sub-sector in Nigeria," 2014, www. mpra.ub.uni-muenchen.de, accessed on 21/09/18.

[3] C. Monyei and A. Adewumi, "Demand Side Management potentials for mitigating energy poverty in South Africa," Energy Policy, vol. 111, pp. 298-311, 2017.

https://doi.org/10.1016/j.enpol.2017.09.039

[4] E. Growth Plan, "Economic Recovery and Growth Plan 2017-2020, Federal Republic and Growth Plan 2017-2020, Federal Republic of Nigeria, Ministry of Budget and National Planning," ed, 2017.

[5] A. F. Adenikinju, "Electric infrastructure failures in Nigeria: a survey-based analysis of the costs and adjustment responses," Energy policy, vol. 31, pp. 1519-1530, 2003. https://doi.org/10.1016/S0301-4215(02)00208-2

[6] S. O. Oyedepo, "Energy and sustainable development in Nigeria: the way forward," Energy, Sustainability and Society, vol. 2, p. 15, 2012.

https://doi.org/10.1186/2192-0567-2-15

[7] G. Tyler, "Public and Private Electricity Provision as a Barrier to Manufacturing Competitiveness: Africa Region Findings, World Bank, March," ed, 2002.

[8] M. O. Oseni, "An analysis of the power sector performance in Nigeria," Renewable and Sustainable Energy Reviews, vol. 15, pp. 4765-4774, 2011.

https://doi.org/10.1016/j.rser.2011.07.075

[9] S. O. Oyedepo, "On energy for sustainable development in Nigeria," Renewable and sustainable energy reviews, vol. 16, pp. 2583-2598, 2012.

https://doi.org/10.1016/j.rser.2012.02.010

[10] B. N. Iyke, "Electricity consumption and economic growth in Nigeria: A revisit of the energy-growth debate," Energy Economics, vol. 51, pp. 166-176, 2015.

https://doi.org/10.1016/j.eneco.2015.05.024

[11] L. N. Chete, J. O. Adeoti, F. M. Adeyinka, and O. Ogundele, "Industrial development and growth in Nigeria: Lessons and challenges," WIDER Working Paper2014., www. hdl.handle.net, accessed on $20 / 01 / 19$ 
[12] D. Ndiaye and K. Gabriel, "Principal component analysis of the electricity consumption in residential dwellings," Energy and buildings, vol. 43, pp. 446-453, 2011.

https://doi.org/10.1016/j.enbuild.2010.10.008

[13] R. Platon, V. R. Dehkordi, and J. Martel, "Hourly prediction of a building's electricity consumption using case-based reasoning, artificial neural networks and principal component analysis," Energy and Buildings, vol. 92, pp. 10-18, 2015. https://doi.org/10.1016/j.enbuild.2015.01.047

[14] L. Burgas, J. Melendez, and J. Colomer, "Principal component analysis for monitoring electrical consumption of academic buildings," Energy Procedia, vol. 62, pp. 555-564, 2014. https://doi.org/10.1016/j.egypro.2014.12.417

[15] J. C. Lam, K. K. Wan, K. Cheung, and L. Yang, "Principal component analysis of electricity use in office buildings," Energy and buildings, vol. 40, pp. 828-836, 2008.

https://doi.org/10.1016/j.enbuild.2007.06.001

[16] N. Ismail and S. Abdullah, "Principal component regression with artificial neural network to improve prediction of electricity demand," Int. Arab J. Inf. Technol., vol. 13, pp. 196-202, 2016.

[17] E. Saccenti and J. Camacho, "Determining the number of components in principal components analysis: A comparison of statistical, crossvalidation and approximated methods," Chemometrics and Intelligent Laboratory Systems, vol. 149, pp. 99-116, 2015.

https://doi.org/10.1016/j.chemolab.2015.10.006

[18] H. Abdi and L. J. Williams, "Principal component analysis," Wiley interdisciplinary reviews: computational statistics, vol. 2, pp. 433-459, 2010.

https://doi.org/10.1002/wics.101

[19] A.-I. Petrişor, I. Ianoş, D. Iurea, and M.-N. Văidianu, "Applications of principal component analysis integrated with GIS," Procedia Environmental Sciences, vol. 14, pp. 247-256, 2012.

https://doi.org/10.1016/j.proenv.2012.03.024

[20] S. M. Al-Alawi, S. A. Abdul-Wahab, and C. S. Bakheit, "Combining principal component regression and artificial neural networks for more accurate predictions of ground-level ozone," Environmental Modelling \& Software, vol. 23, pp. 396-403, 2008.

https://doi.org/10.1016/j.envsoft.2006.08.007

[21] J. Zhang, X.-y. Yang, F. Shen, Y.-w. Li, H. Xiao, H. Qi, et al., "Principal component analysis of electricity consumption factors in China," Energy Procedia, vol. 16, pp. 1913-1918, 2012. https://doi.org/10.1016/j.egypro.2012.01.292

[22] A. E. Akinlo, "Electricity consumption and economic growth in Nigeria: evidence from cointegration and co-feature analysis," Journal of Policy Modeling, vol. 31, pp. 681-693, 2009. https://doi.org/10.1016/j.jpolmod.2009.03.004

[23] A. B. Onakoya, A. O. Onakoya, O. A. Jimi-Salami, and B. O. Odedairo, "Energy consumption and
Nigerian economic growth: An empirical analysis," European Scientific Journal, ESJ, vol. 9, 2013. 